\title{
The Application of Uncertainty Theory in Vehicle Collision Accident Reconstruction
}

\author{
Su-yang Ji ${ }^{1}$, Jing-jing $\mathrm{Xia}^{2}$ \\ ${ }^{1}$ School of Mechanical and Power Engineering, Nanjing Tech University, Nanjing 210000, China; \\ ${ }^{2}$ School of Traffic Science Specialty, Huaiyin Institute of Technology, Huaian 223003, China
}

\begin{abstract}
The theory of uncertainty analysis technique is presented. A kinect model is established, the uncertainty factors such as adhesion coefficient and brake trace are considered. The method of uncertainty theory is applied to analyze the uncertainty of velocity calculation in accident reconstruction, and then the practicability of the method was also demonstrated by a true accident case.
\end{abstract}

\section{Introduction}

According to the 2015 China Automobile Safety Development Report, in 2013, a total of 198 thousand and 400 traffic accidents involving casualties, resulting in 58 thousand and 500 deaths, 213 thousand and 700 people were injured [1].Accident reconstruction not only can accurately carry out accident investigation and responsibility identification, but also has a great help to accident prevention. Therefore, it is very important to realize the accurate representation of vehicle collision accident. But because of the complexity of vehicle collision accidents, There is a lot of uncertainty in speed identification. Uncertainty theory is applied in the paper, and discussed the uncertain parameters in accidents, according to the calculated uncertainty, calculate the range before the collision speed, make more accurate determination of the cause of the accident.

\section{Uncertainty theory}

Uncertainty is usually used to characterize the dispersion of the measured values. In general terms, the measurement uncertainty is defined as the degree to which the measurement results are correct. There are all kinds of measurement errors in the actual accident measurement, the results always have a certain degree of uncertainty, we can only get the scope which can be used to describe the degree of uncertainty [2].

\subsection{Uncertainty description}

Measurement uncertainty is the degree to describe uncertainty of the measurement results, Suppose that we need to measure the value of $\mathrm{Y}$ related to the quantity of input $x_{i}(i=1,2 \ldots)$ with uncertainty, $x_{i}$ is usually a random variable. recorded the multiple functions as:

$$
Y=f\left(x_{1}, x_{2}, x_{3}, \ldots, x_{n}\right) .
$$

if and only if the approximate solution $y$ to be obtained when the optimal value of each input $\mathrm{x}_{\mathrm{i}}$ is taken, write down $\mathrm{y}$ as:

$$
y=f\left(x_{1}, x_{2}, x_{3}, \ldots, x_{n}\right) \text {. }
$$

Therefore, the uncertainty of the results $(y)$ is derived fromx $_{i}(i=1,2, \ldots, n)$, In other words, the uncertainty $u_{y}$ of $y$ depends on the degree of uncertainty $u_{\left(x_{i}\right)}$ of each

$$
\text { input } \mathrm{x}_{\mathrm{i}}(\mathrm{i}=1,2, \ldots, \mathrm{n}) \text {. }
$$

\subsection{Method for evaluating uncertainty}

There are two kinds of evaluation method of uncertainty, the Type A and Type B evaluation of uncertainty, they are show in Figure 1.

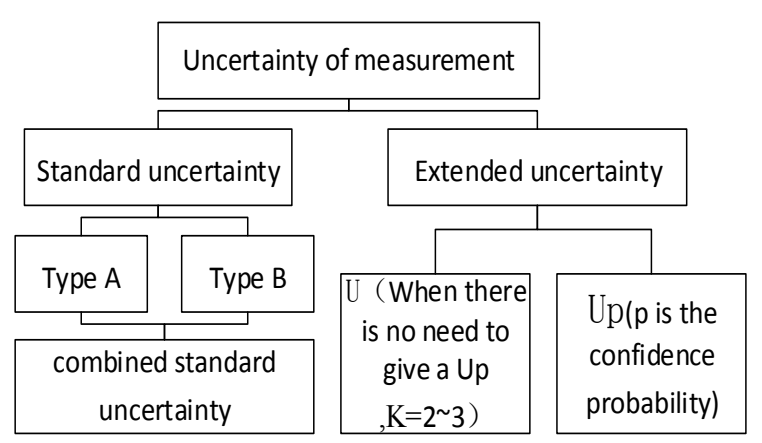

Figure 1. Structure of measurement uncertainty

The Type A evaluation of uncertainty assessed the uncertainty based on taking statistical analysis on 
observation while the Type B evaluation of uncertainty taking other methods. Such as long-term practical experience, common sense or reference books, etc.

In this paper, the Type B evaluation of uncertainty was been adopted. The calculation method is given.

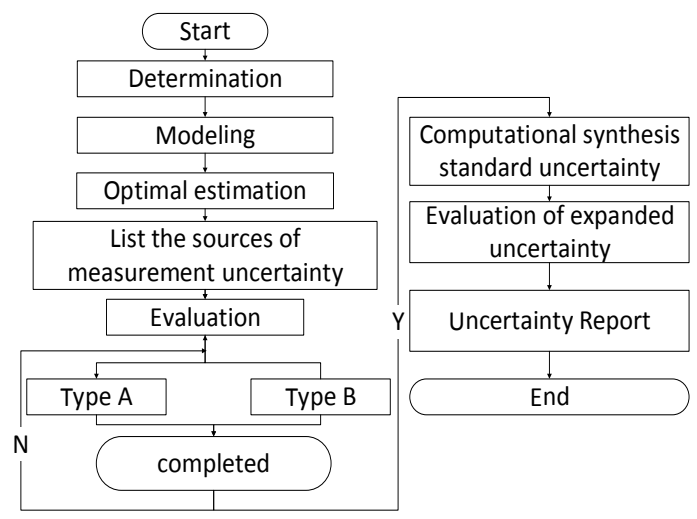

Figure 2. Steps for the evaluation of uncertainty in measurement

\subsection{Standard uncertainty calculation}

If the half width dispersion interval $x_{i}$ of the known estimate $a_{i}$ is given, And the probability of falling in the interval $\left[\mathrm{x}_{\mathrm{i}}-\mathrm{a}_{\mathrm{i}}, \mathrm{x}_{\mathrm{i}}+\mathrm{a}_{\mathrm{i}}\right]$ was $100 \%$, Then estimate the distribution, we can get the uncertainty of $\mathrm{x}_{\mathrm{i}}$ was $_{\mathrm{x}_{\mathrm{i}}}=$ $\mathrm{a}_{\mathrm{i}} / \mathrm{k}_{\mathrm{i}}, \mathrm{k}_{\mathrm{i}}$ means coverage factor, generally taken equal to $2-3[3]$.

\subsection{The calculation of combined standard uncertainty}

The standard uncertainty component of a function $\mathrm{y}$ caused by any standard uncertainty $\mathrm{x}_{\mathrm{i}}$ is recorded as:

$$
\mathrm{u}_{\mathrm{y}_{\mathrm{i}}}=\left|\frac{\partial \mathrm{y}}{\partial \mathrm{x}_{\mathrm{i}}}\right| \mathrm{u}_{\mathrm{x}_{\mathrm{i}}}=\left|\mathrm{c}_{\mathrm{i}}\right| \mathrm{u}_{\mathrm{x}_{\mathrm{i}}}
$$

$c_{i}$ means transmission coefficient, which used to describe the change in the estimated value of the output $y$ caused by the unit variation of the estimated value of the input $x_{i}$, Played a role in the spread of uncertainty.

Some measurements are direct, The standard uncertainty of each component is uncorrelated, Synthesis by combination of square root. For most situations the inputs are uncorrelated, Then synthesis with the following formula:

$$
\begin{aligned}
& \mathrm{u}_{\mathrm{c}}(\mathrm{y})=\sqrt{\sum_{\mathrm{i}=1}^{\mathrm{n}}\left(\frac{\partial_{\mathrm{f}}}{\partial \mathrm{x}_{\mathrm{i}}}\right)^{2} \mathrm{u}_{\mathrm{x}_{\mathrm{i}}}{ }^{2}} \\
& =\sqrt{\sum_{\mathrm{i}=1}^{\mathrm{n}} \mathrm{u}_{\mathrm{i}}^{2}(\mathrm{y})}
\end{aligned}
$$

From the above formula we can know, Combined standard uncertainty means the uncertainty caused by input in the form of superposition of square. When one of the input value has the most uncertainty, The uncertainty of the parameters will be significantly greater than other parameters, means this parameter uncertainty has the biggest impact, Others confirmed to belong to small uncertainty.

\subsection{The calculation of the expanded uncertainty}

In fact, the confidence probability of the standard uncertainties often in a low position, For example, the confidence probability of normal distribution of combined standard uncertainty is $68 \%$.In order to make the measurement more reliable, we will need to expand the interval of confidence probability, we can use coverage factorkmultiplied bycombined standard uncertainty $\mathrm{u}_{\mathrm{c}}(\mathrm{y})$, so that we can get the expanded uncertainty.

$$
\mathrm{U}(\mathrm{y})=\mathrm{ku}_{\mathrm{c}}(\mathrm{y})
$$

The value of the multivariate function $Y$ obtained at this time can be written as

$$
\mathrm{Y}=\mathrm{y} \pm \mathrm{U}
$$

It means the best value of multivariate function $Y$ with maximum probability will falls in the range $[\mathrm{Y}-$ $\mathrm{U}, \mathrm{Y}+\mathrm{U}]$

\section{Calculation method of vehicle speed and evaluation of uncertainty based on momentum conservation}

\subsection{The basic theory of momentum conservation in vehicle collision}

The law of conservation of momentum is the most common rule in nature. In the actual traffic accident, The collision is often made up of two objects, to establish impact models:

$$
\mathrm{m}_{1} \mathrm{v}_{10}+\mathrm{m}_{2} \mathrm{v}_{20}=\mathrm{m}_{1} \mathrm{v}_{1}+\mathrm{m}_{2} \mathrm{v}_{2}
$$

Taking into account the fact that the collision is often similar to the plane collision, $0-x y$ Coordinate system can be selected, the formula (2-1) can be written as:

$$
\begin{aligned}
& \mathrm{m}_{1} \mathrm{v}_{10 \mathrm{x}}+\mathrm{m}_{2} \mathrm{v}_{20 \mathrm{x}}=\mathrm{m}_{1} \mathrm{v}_{1 \mathrm{x}}+\mathrm{m}_{2} \mathrm{v}_{2 \mathrm{x}} \\
& \mathrm{m}_{1} \mathrm{v}_{10 \mathrm{y}}+\mathrm{m}_{2} \mathrm{v}_{20 \mathrm{y}}=\mathrm{m}_{1} \mathrm{v}_{1 \mathrm{y}}+\mathrm{m}_{2} \mathrm{v}_{2 \mathrm{y}}
\end{aligned}
$$

The speed can be calculated according to the brake print formula

$$
\mathrm{v}_{\mathrm{j}}=\sqrt{2 \varphi g S_{\mathrm{j}}}
$$

Simultaneous formula (9) and formula (10), we can get $\mathrm{v}_{10}$ and $\mathrm{v}_{20}$

\subsection{The uncertain parameters in vehicle accident}

In the foregoing content, we assumed the length of the brake marks, the friction coefficient and the velocity component angle are already known. However in the 
actual traffic accident, these parameters can not be measured accurately, there is great uncertainty .Observe the brake formula (11), Acceleration of gravity $g$ is a constant, but the coefficient of friction $\varphi$ and the length of the brake marksall have uncertainty. Their values are $\varphi_{\min } \leq \varphi \leq \varphi_{\max }, \mathrm{S}_{\min } \leq \mathrm{S} \leq \mathrm{S}_{\max }$. Therefore, the instantaneous velocity of the vehicle can be divided as follows:

$$
\sqrt{2 \varphi_{\min } g S_{\min }} \leq \mathrm{v} \leq \sqrt{2 \varphi_{\max } \mathrm{gS} \max }
$$

\section{Accident case analysis}

A van along the road from west to east to $\mathrm{DP} \mathrm{Rd}$ and XA Rd .intersection, hit a garbage truck which was along the XA Rd from north to south .Field inspection map shows, Before the collision the truck had brake marks on the road, began to appear the break seal $\mathrm{S}_{1}=$ $15.6 \mathrm{~m}$ of right side wheels, then produced the break sealS $_{2}=4.4 \mathrm{~m}$ of both side, At this time the two vehicles collided, there was no break seal of garbage truck before the collision, than two cars move forward together and have brake seal $S_{3}=3 \pm 0.5 \mathrm{~m}$ after the collision, garbage truck

In the above formula, $\mathrm{m}_{1}$ means quality of car $\mathrm{A}$, $\mathrm{m}_{2}$ means quality of car $\mathrm{B}, \mathrm{v}_{10}$ means speed of car $\mathrm{A}$ before collision, $v_{20}$ means speed of car $B$ before collision, $v_{1}$ means speed of car $A$ after collision, $v_{2}$ means speed of car B after collision.

overturned eventually .both of their driving direction are south by east after the collision, by supplementary measure, the angle between the brake traces and the north south direction after collision is $\alpha=20^{\circ}$, The accident occurred on the road is a newly built asphalt pavement.

Table 1. Vehicle parameters

\begin{tabular}{|c|c|c|c|}
\hline Vehicle & $\begin{array}{c}\text { Curb } \\
\text { weight }\end{array}$ & $\begin{array}{c}\text { Total } \\
\text { Passenger }\end{array}$ & $\begin{array}{c}\text { Total mass after } \\
\text { collision }\end{array}$ \\
\hline Van & $1920 \mathrm{~kg}$ & 2 & $2050 \mathrm{~kg}$ \\
\hline Truck & $10490 \mathrm{~kg}$ & 1 & $10555 \mathrm{~kg}$ \\
\hline
\end{tabular}

\subsection{Determination of related parameters and calculation of vehicle speed}

This is the scene graph derived from police who deal with traffic accidents, the driving direction and end position of the accident and their respective brake marks are given.

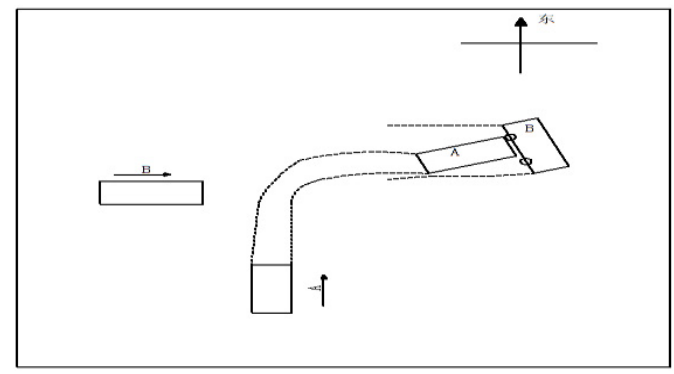

Figure 3. Schematic diagram of the accident scene
According to literature, we can know the range of sliding attachment coefficient is $\varphi_{\mathrm{S} 1}=0.60 \sim 0.70, \varphi_{\mathrm{S} 2}=$ $0.80 \sim 0.90=\varphi_{\mathrm{S} 3}$ from Table 2[3].

Table 2. Table of reference value of longitudinal slip adhesion coefficient of automobile.

\begin{tabular}{|c|c|c|c|c|c|}
\hline \multirow{2}{*}{$\begin{array}{c}\text { Pavement } \\
\text { behaviour }\end{array}$} & \multicolumn{2}{c|}{ Dry } & \multicolumn{2}{c|}{ Damp } \\
\cline { 3 - 6 } \multicolumn{2}{|c|}{} & $\begin{array}{c}\leq 48 \mathrm{~km} \\
/ \mathrm{h}\end{array}$ & $\begin{array}{l}\geq 48 \mathrm{~km} \\
/ \mathrm{h}\end{array}$ & $\begin{array}{l}\leq 48 \mathrm{~km} \\
/ \mathrm{h}\end{array}$ & $\begin{array}{l}\geq 48 \mathrm{~km} \\
/ \mathrm{h}\end{array}$ \\
\hline \multirow{4}{*}{ concrete } & \multirow{2}{*}{ new } & $\begin{array}{c}0.80-1 . \\
00\end{array}$ & $\begin{array}{c}0.70-0 . \\
85\end{array}$ & $\begin{array}{c}0.50-0 . \\
80\end{array}$ & $\begin{array}{c}0.40-0 \\
.75\end{array}$ \\
\cline { 2 - 6 } & \multirow{2}{*}{ old } & $\begin{array}{c}0.60-0 . \\
80\end{array}$ & $\begin{array}{c}0.60-0 . \\
75\end{array}$ & $\begin{array}{c}0.45-0 . \\
70\end{array}$ & $\begin{array}{c}0.45-0 \\
.65\end{array}$ \\
\hline \multirow{3}{*}{ Asphalt } & \multirow{2}{*}{ new } & $\begin{array}{c}0.80-0 . \\
90\end{array}$ & $\begin{array}{c}0.60-0 . \\
70\end{array}$ & $\begin{array}{c}0.50-0 . \\
80\end{array}$ & $\begin{array}{c}0.45-0 \\
.75\end{array}$ \\
\cline { 2 - 6 } & \multirow{2}{*}{ old } & $\begin{array}{c}0.60-0 . \\
80\end{array}$ & $\begin{array}{c}0.55-0 . \\
70\end{array}$ & $\begin{array}{c}0.45-0 . \\
70\end{array}$ & $\begin{array}{c}0.40-0 \\
.65\end{array}$ \\
& & & 70 & & \\
\hline
\end{tabular}

According to the law of conservation of momentum to calculate the speed of the collision of two cars, before the collision, truck A from west to East, the garbage truck B from north to south, then the instantaneous speed of van in collision $\mathrm{v}_{1}$ is

$$
\begin{gathered}
\mathrm{m}_{1} \mathrm{v}_{1}=\left(\mathrm{m}_{1}+\mathrm{m}_{2}\right) \mathrm{v}_{\mathrm{c}} \sin \alpha \\
\mathrm{m}_{2} \mathrm{v}_{2}=\left(\mathrm{m}_{1}+\mathrm{m}_{2}\right) \mathrm{v}_{\mathrm{c}} \cos \alpha \\
\mathrm{v}_{1}=\frac{\mathrm{m}_{1}+\mathrm{m}_{2}}{\mathrm{~m}_{1}} \mathrm{v}_{\mathrm{c}} \sin \alpha=14.87 \mathrm{~m} / \mathrm{s}
\end{gathered}
$$

According to the law of conservation of energy, the speed of van before braking $\mathrm{v}_{10}$ is

$$
\frac{1}{2} \mathrm{~m}_{1} \mathrm{v}_{10}^{2}=\frac{1}{2} \mathrm{~m}_{1} \mathrm{~g} \varphi_{\mathrm{s}_{1}} \mathrm{~s}_{1}+\mathrm{m}_{1} \mathrm{~g} \varphi_{\mathrm{s}_{2}}+\frac{1}{2} \mathrm{~m}_{1} \mathrm{v}_{1}^{2}
$$

\subsection{Evaluation of uncertainty in vehicle speed identification.}

Based on the introduction of uncertainty in the paper, take a confidence level at 0.94 , At this point the corresponding $\mathrm{K}=2[6]$. the calculation results of the above parameters are presented in Table 3.

Table 3. Van speed uncertainty component evaluation form

\begin{tabular}{|c|c|c|}
\hline Parameter & $\varphi_{\mathrm{S}_{2}}$ & $\mathrm{~S}_{3}$ \\
\hline Range & 0.05 & 0.3 \\
\hline coverage factor $(\mathrm{k})$ & 2 & 2 \\
\hline $\mathrm{u}\left(\mathrm{v}_{\mathrm{i}}\right)=\mathrm{a}_{\mathrm{i}} / \mathrm{k}_{\mathrm{i}}$ & 0.025 & 0.15 \\
\hline $\mathrm{u}^{\prime}\left(\mathrm{v}_{\mathrm{i}}\right)$ & 0.0312 & 0.0109 \\
\hline Propagation coefficient & 8.7456 & 2.4779 \\
\hline $\begin{array}{c}\text { Relative standard } \\
\text { uncertainty component }\end{array}$ & 0.0156 & 0.0054 \\
\hline
\end{tabular}

According to the above parameters, the relative standard uncertainty of $\mathrm{v}_{10}$ is:

$$
\mathrm{u}_{\mathrm{v} 10}=\sqrt{\sum_{\mathrm{i}=1}^{2} \mathrm{u}^{\prime 2}\left(\mathrm{v}_{\mathrm{BOI}}\right)}=1.65 \%
$$


Expanded uncertainty is:

The range ofv $v_{10}$ is:

$$
\mathrm{U}^{\prime}=\mathrm{Ku}_{\mathrm{v} 10}=2 \times 1.65 \%=3.3 \%
$$

$$
\begin{aligned}
\mathrm{v}_{10}=\mathrm{v}_{1} & \pm \mathrm{v}_{1} \mathrm{U}^{\prime}=(53.53 \pm 1.77) \mathrm{km} / \mathrm{h} \\
& =51.76 \sim 55.30 \mathrm{~km} / \mathrm{h}
\end{aligned}
$$

Similarly,

$$
\mathrm{v}_{20}=(28.56 \pm 0.94) \mathrm{km} / \mathrm{h}=27.62 \sim 29.5 \mathrm{~km} / \mathrm{h}
$$

\section{Summary}

Through the above analysis, selecting appropriate uncertain parameters for uncertainty evaluation, the identification results of vehicle speed and the relevant judicial authorities are consistent, and has higher accuracy. The research shows that the uncertainty theory has certain applicability in the automobile accident reconstruction, and it can be used in the actual traffic accident. However, the calculation of uncertainty is more complicated and needs further study.

\section{Acknowledgments}

This work was financially supported by The Jiangsu provincial production and research cooperation project,
Research on the key technology of vehicle crash accident reconstruction, BY2015051-10.

\section{References}

1. China Automotive Technology Research Center.China automotive safety development report:2015[M].Social science literature press, (2015).

2. Yuan Quan, LI Yi-bing.Uncertainty evaluation on the energy method of vehicle traffic accident reconstruction[J].China Journal of Highway and Transport, 15(1):110-112, (2002).

3. GA/T643-2006, typical traffic accident vehicle speed technology in the form of identification[S].

4. Wang Ji-zhong.Study on the Interaction of Tire Tread Element with Road Surface and Tread Element Design[D].Changchun:Jilin University of Technology, (2000).

5. Zhuang Ji-de.Principles of Automobile Tyre[M].Beijing:Beijing Institute of Technology Press, (1996).

6. Lu Zhi-xiong, Yang Rui.Automobile accident identification[M].China Machine Press, (2013). 